\title{
Pulse pressure tracking from adolescence to young adulthood: contributions to vascular health
}

\author{
Xavier Melo , Diana A. Santos, Rui Ornelas, Bo Fernhall, Helena Santa-Clara \\ \& Luís B. Sardinha
}

To cite this article: Xavier Melo, Diana A. Santos, Rui Ornelas, Bo Fernhall, Helena SantaClara \& Luís B. Sardinha (2017): Pulse pressure tracking from adolescence to young adulthood: contributions to vascular health, Blood Pressure, DOI: 10.1080/08037051.2017.1360724

To link to this article: http://dx.doi.org/10.1080/08037051.2017.1360724

$$
\text { 曲 Published online: } 28 \text { Jul } 2017 .
$$

Submit your article to this journal

Q View related articles $\sqsubset$

View Crossmark data $\nearrow$ 


\title{
Pulse pressure tracking from adolescence to young adulthood: contributions to vascular health
}

\author{
Xavier Melo ${ }^{a, b} \mathbb{D}$, Diana A. Santos ${ }^{a}$, Rui Ornelas ${ }^{a, c}$, Bo Fernhall ${ }^{d}$, Helena Santa-Clara ${ }^{a}$ and Luís B. Sardinha ${ }^{a}$ \\ ${ }^{\text {a}}$ Faculdade de Motricidade Humana, CIPER-Centro Interdisciplinar de Estudo da Performance Humana, Universidade de Lisboa, Lisboa, \\ Portugal; ${ }^{b}$ Ginásio Clube Português, Lisboa, Portugal; 'Departamento de Educação Física e Desporto, Universidade da Madeira, \\ Funchal, Madeira; 'Integrative Physiology Laboratory, College of Applied Health Sciences, University of Illinois at Chicago, Chicago, IL, \\ USA
}

\begin{abstract}
Purpose: We examined whether exposure to high PP in adolescence predicts carotid artery intima-media thickness (IMT) and stiffness indices at young adulthood.

Methods: Seventy-nine participants had their brachial systolic (SBP) and diastolic blood (DBP) pressures taken at the age of 15-16 years and later at young adulthood (29-31 years). Carotid IMT, distensibility and stiffness index $\beta$ were measured at young adulthood. Linear and logistical regression analysis were performed.

Results: PP at adolescence and at young adulthood predicted vascular health independently of sex, body mass index, and mean arterial pressure, explaining up to $37 \%$ of the variance. When analyzing its single constituents, at adolescence DBP was more predictive of vascular health, whereas DBP and SBP were equally important at young adulthood. Adolescents with high PP were at risk for increased carotid IMT (OR: 4.04-4.09), even if PP decreased at young adulthood. Young adults with high PP were at risk for increased stiffness regardless of adolescence PP (OR: 4.64-7.35).

Conclusion: PP at adolescence and young adulthood may be a better predictor of early pathological changes in carotid artery structure and stiffness. Whereas carotid IMT in young adults appears to be influenced by PP at adolescence, carotid stiffness depends primarily on current PP.
\end{abstract}

\section{ARTICLE HISTORY}

Received 1 April 2017

Revised 30 June 2017

Accepted 22 July 2017

\section{KEYWORDS}

Atherosclerosis; arteriosclerosis; blood pressure; intimamedia thickness; arterial stiffness; epidemiology

\section{Introduction}

Vascular changes including atherosclerosis begin early in life as a silent, asymptomatic disease process and are associated with cardiovascular risk factors [1], which persist or track from childhood to adulthood and are predictive of cardiovascular disease risk in adults [2]. Studies among the young have shown that blood pressure has a pivotal role in functional, mechanical, and structural early subclinical manifestations of cardiovascular pathology measured in adulthood [3-10]. Thus, not only a life-course rather than a single time-point approach to the study of the early determinants of arterial stiffness is needed, as the evaluation of subclinical manifestations of cardiovascular pathology, such as arterial stiffness and carotid intima-media thickness, and its predictors may help identify asymptomatic individuals at risk.

In the past, childhood systolic and diastolic blood pressures and their changes have been the primary mechanical factors predicting arterial stiffness in adulthood [4,6-9]. However, if increased blood pressure acts as a mechanical factor with deleterious consequences on the arterial wall, the totality of the blood pressure curve should be considered to evaluate the risk [11]. Other hemodynamic indices originated from pulsatile pressure are particularly relevant for cardiac complications but have scarcely been taken into account when evaluating childhood blood pressure as a determinant of arterial structure and stiffness in adulthood [5]. Increased pulse pressure (PP) is a powerful independent predictor of cardiovascular end points [12]. There are two major components of PP: first, ventricular ejection interacts with the viscoelastic properties of the large arteries (direct) and second, wave reflection (indirect) and its impact on the augmented pressure $[13,14]$. PP reflects stiffness of the large arteries and increases with advancing age from 50 years onward, because of opposing trends in systolic and diastolic blood pressures [15]. Although a

CONTACT Xavier Melo xaviermelo@fmh.ulisboa.pt $\mathrm{E}$ Faculdade de Motricidade Humana, Universidade de Lisboa, Estrada da Costa, Sala 8-Pavilhão Lord, Cruz Quebrada, 1495-688 Lisbon, Portugal

(C) 2017 Informa UK Ltd, trading as Taylor \& Francis Group 
large PP as measured at the brachial artery with the use of the cuff method is not an accurate representation of the proximal PP, it is a readily available and it does suggest a stiffened aorta [16]. However, limited data is available with respect to whether and to what extent PP and PP changes from childhood to adulthood are associated with early subclinical manifestations of cardiovascular pathology in young healthy populations [4]. Therefore, the purpose of this investigation was to examine whether exposure to high PP in adolescence predicts carotid artery intima-media thickness (IMT) and stiffness indices in young adulthood.

\section{Methods}

\section{Participants}

The European Youth Heart Study, a community-based research of the natural history of cardiovascular disease beginning in childhood and adolescence, is a multi-national study with a mixed cross-sectional and longitudinal approach [17] in which several countries participate: Denmark, Estonia, Portugal and Norway.

A cross-sectional survey was conducted in 1999/ 2000 in 15-year-old adolescents $(n=593)$ from Madeira Island, Portugal. The adolescents were randomly selected from 29 primary schools belonging to the 10 municipalities. The schools were also randomly selected from 152 schools based on distribution throughout the municipality and socioeconomic status. The participation rate was $88.7 \%$ in 2000 . From 2013 to 2016 we conducted a 14-year follow-up analysis in a sub-sample of participants $(n=79)$ with a mean age of $30.05 \pm 0.06$. All evaluations were conducted in the Department of Physical Education and Sport of Madeira University.

Adolescents provided assent for their participation and informed consent was obtained from their legal guardians in 1999/2000. Informed consent was obtained from young adults in the follow-up. The study protocol conforms to the ethical guidelines of the 1975 Declaration of Helsinki as reflected in a priori approval by the Ethics Committee of the Faculdade de Motricidade Humana - Universidade de Lisboa.

\section{Anthropometry}

Weight and height were measured while the participants were wearing light clothing and no shoes, using standard techniques. Height was measured to the nearest $0.5 \mathrm{~cm}$ using a Seca stadiometer
(Medical Scales and Measuring Systems Seca ltd, Birmingham, UK) and weight was measured to the nearest $0.1 \mathrm{~kg}$ with a calibrated Seca beam balance scale (Medical Scales and Measuring Systems Seca ltd, Birmingham, UK). Body mass index was calculated as the weight in kilogrammes divided by the square of height in meters $\left(\mathrm{kg} / \mathrm{m}^{2}\right)$.

\section{Brachial blood pressure}

Resting systolic and diastolic blood pressures were measured after $5 \mathrm{~min}$ of lying rest, with a Dinamap XL Vital signs monitor, (Johnson \& Johnson Medical Inc., Arlington, TX, USA). Five measurements were taken at 2 min intervals and the mean of the final 3 measurements was considered. Mean arterial pressure was calculated as $1 / 3 \mathrm{PP}+$ diastolic blood pressure. Pulse pressure was calculated as systolic-diastolic blood pressures.

\section{Carotid artery stiffness indices and blood pressure by vascular ultrasound}

The carotid artery stiffness measurement was conducted at adulthood, with the participant in the supine position after at least a 15 -min resting period before. We used an ultrasound scanner equipped with a linear $13 \mathrm{MHz}$ probe (MyLab One, Esaote, Italy) with Quality Arterial Stiffness technology, based on radio frequency signal in a common carotid artery segment $\sim 1 \mathrm{~cm}$ before the bifurcation. This software used a complex algorithm that could process all data coming from the arterial wall as radiofrequency signals, automatically measuring the change in arterial diameter between the systolic and diastolic phases. During imaging of the common carotid artery, the examiner obtained real-time feedback on measurement to optimize the probe position to have the best scan plane with respect to the distension and diameter. Theoretically, carotid diameter waveforms were assessed by means of ultrasound and converted to carotid pressure waveforms using an empirically derived exponential relationship between pressure and arterial cross-section. The derived right carotid pressure waveform was calibrated to right brachial end diastolic and mean arterial pressure by iteratively changing the wall rigidity coefficient. This allows the calculation of carotid stiffness indices: distensibility coefficient $(1 / \mathrm{KPa})$ and stiffness index $\beta$. Distensibility coefficient is the fractional change in cross-sectional area relative to the change in arterial pressure. 
Distensibility coefficient (Distensibility) was calculated as:

$$
\text { Distensibility }=\frac{\Delta \mathrm{A}}{\mathrm{A} \cdot \Delta \mathrm{PP}}=\frac{2 \cdot \mathrm{D} \cdot \Delta \mathrm{D}+\Delta \mathrm{D}^{2}}{\mathrm{D}^{2} \cdot \Delta \mathrm{PP}}
$$

Where A: diastolic area; $\Delta \mathrm{A}$ : change of area in systole, $\mathrm{D}$ : diastolic diameter and $\Delta \mathrm{D}$ : change of diameter in systole.

Stiffness index $\beta$ was expressed as:

$$
\beta=\frac{\mathrm{D} \cdot \ln \left(\frac{\mathrm{Ps}_{\mathrm{s}}}{\mathrm{P}_{\mathrm{d}}}\right)}{\Delta \mathrm{D}}
$$

Where Ps and Pd are carotid systolic and diastolic pressure respectively [18]. Distensibility coefficient and stiffness index $\beta$ are reciprocal but they reflect different arterial responses.

\section{Statistical analyses}

Descriptive values were expressed as mean \pm standard deviation. Quantitative variables were examined for normality, skewness, and kurtosis by performing the Shapiro-Wilk test of normality, visual inspection of normal quantile and histogram plots, and kurtosis and skewness summary statistics. Baseline group characteristics were compared with paired-sample t-test. Multiple linear regression analysis was used to estimate the association between exposure variables at young adulthood (wall thickness and carotid stiffness indices | dependent variables) and (1) hemodynamic indices (PP and mean arterial pressure), and (2) single measures of blood pressure (systolic and diastolic blood pressure), measured at adolescence and young adulthood (independent variables). Beta's and 95\%CI were calculated for all models considering sex, and body mass index as confounders by including these variables as covariates in the regression models.
The variance inflation factor was used to assess the extent to which the variances of the estimated coefficients were inflated. Logistical regression models (set by sex-specific tertiles) were used to examine the associations between trajectories of (1) PP, and (2) SBP and DBP, and exposure outcomes. The persistently low PP category was used as the reference group [odds ratio $(\mathrm{OR})=1$ ]. Sex, mean arterial pressure, and body mass index changes were considered confounders and included as covariates in the regression models.

Statistical significance level was set at $p<.05$ for all tests. The statistical analyses were computed and analyzed by a certified researcher using the SPSS Statistics 22.0 (SPSS Inc., Chicago, IL, USA).

\section{Results}

The characteristics of the study population are shown in Table 1. Sex differences were mainly found in body composition and hemodynamic variables at young adulthood $(p<.05)$. Body mass index, systolic and diastolic blood pressures, and mean arterial pressure increased from adolescence to young adulthood $(p<.05)$. The prevalence of overweight and obesity in adolescence was $17.5 \%$ and increased to $45 \%$ in young adulthood $(p<.05)[19,20]$. None were hypertensive at adolescence or young adulthood.

Results from linear regression analysis between hemodynamic indices and single measures of blood pressure, measured at adolescence and young adulthood, with carotid IMT and arterial stiffness indices at young adulthood are presented in Table 2. PP at adolescence was significantly associated with all exposure outcomes at young adulthood, independently of mean arterial pressure, sex, and body mass index, explaining up to $15 \%$ of the variance in distensibility

\begin{tabular}{|c|c|c|c|c|}
\hline & \multicolumn{2}{|c|}{ Adolescence } & \multicolumn{2}{|c|}{ Adulthood } \\
\hline & Males & Females & Males & Females \\
\hline$n$ & 46 & 34 & 46 & 34 \\
\hline Age (years) & $15.68 \pm 0.32$ & $15.62 \pm 0.34$ & $29.96 \pm 0.47^{*}$ & $30.18 \pm 0.52^{*}$ \\
\hline Body Mass Index $\left(\mathrm{kg} / \mathrm{m}^{2}\right)$ & $21.18 \pm 2.74$ & $21.45 \pm 2.69$ & $25.91 \pm 3.65^{*}$ & $23.41 \pm 3.66^{*}+$ \\
\hline Systolic blood pressure $(\mathrm{mmHg})$ & $107.01 \pm 10.33$ & $103.81 \pm 9.67$ & $115.13 \pm 9.08^{*}$ & $107.00 \pm 8.41^{*} \dagger$ \\
\hline Diastolic blood pressure (mmHg) & $58.95 \pm 6.66$ & $60.38 \pm 6.74$ & $66.76 \pm 7.21 *$ & $65.29 \pm 8.88^{*}$ \\
\hline Mean arterial pressure $(\mathrm{mmHg})$ & $74.97 \pm 6.85$ & $74.86 \pm 6.85$ & $82.88 \pm 6.91^{*}$ & $79.20 \pm 7.93 * \dagger$ \\
\hline Brachial PP (mmHg) & $48.07 \pm 9.03$ & $43.43 \pm 8.11 \dagger$ & $48.38 \pm 8.07$ & $41.71 \pm 7.75 \dagger$ \\
\hline Carotid PP (mmHg) & & & $39.67 \pm 7.12$ & $31.65 \pm 6.36 \dagger$ \\
\hline Carotid IMT (mm) & & & $0.55 \pm 0.09$ & $0.53 \pm 0.08$ \\
\hline Distensibility (1/Kpa) & & & $0.037 \pm 0.009$ & $0.041 \pm 0.009 \dagger$ \\
\hline Stiffness Index $\beta$ & & & $6.38 \pm 1.59$ & $6.14 \pm 1.24$ \\
\hline
\end{tabular}

Table 1. Characteristics of the participants at adolescence and adulthood by sex. 
Table 2. Multivariate association between hemodynamic indices and single measures of blood pressure, measured at adolescence and young adulthood, with carotid IMT and arterial stiffness indices at young adulthood.

\begin{tabular}{|c|c|c|c|c|c|c|c|}
\hline \multirow[b]{2}{*}{ Models } & \multirow[b]{2}{*}{ Time Point } & \multicolumn{2}{|c|}{ Carotid IMT } & \multicolumn{2}{|c|}{ Distensibility } & \multicolumn{2}{|c|}{ Stiffness index $\beta$} \\
\hline & & Beta & $95 \% \mathrm{Cl}$ & Beta & $95 \% \mathrm{Cl}$ & Beta & $95 \% \mathrm{Cl}$ \\
\hline 1 & $\begin{array}{l}\text { Adolescence } \\
\text { Pulse Pressure } \\
\text { Mean Arterial Pressure }\end{array}$ & $\begin{array}{r}0.279 \\
-0.142\end{array}$ & $\begin{array}{r}0.033 \mid 0.526 \\
-0.374 \mid 0.090\end{array}$ & $\begin{array}{r}-0.243 \\
0.001\end{array}$ & $\begin{array}{l}-0.484 \mid-0.003 \\
-0.225 \mid 0.227\end{array}$ & $\begin{array}{r}0.253 \\
-0.152\end{array}$ & $\begin{array}{r}0.005 \mid 0.501 \\
-0.385 \mid 0.081\end{array}$ \\
\hline 2 & $\begin{array}{l}\text { Systolic Blood Pressure } \\
\text { Diastolic Blood Pressure }\end{array}$ & $\begin{array}{r}0.247 \\
-0.303\end{array}$ & $\begin{array}{l}-0.035 \mid 0.530 \\
-0.564 \mid-0.042\end{array}$ & $\begin{array}{r}-0.276 \\
0.183\end{array}$ & $\begin{array}{l}-0.551 \mid-0.001 \\
-0.071 \mid 0.438\end{array}$ & $\begin{array}{r}0.212 \\
-0.290\end{array}$ & $\begin{array}{l}-0.071 \mid 0.495 \\
-0.552 \mid-0.027\end{array}$ \\
\hline 1 & $\begin{array}{l}\text { Adulthood } \\
\text { Pulse Pressure } \\
\text { Mean Arterial Pressure }\end{array}$ & $\begin{array}{r}0.053 \\
-0.086\end{array}$ & $\begin{array}{l}-0.204 \mid 0.309 \\
-0.320 \mid 0.148\end{array}$ & $\begin{array}{l}-0.483 \\
-0.027\end{array}$ & $\begin{array}{l}-0.697 \mid-0.270 \\
-0.222 \mid 0.167\end{array}$ & $\begin{array}{r}0.463 \\
-0.346\end{array}$ & $\begin{array}{r}0.254 \mid 0.672 \\
-0.537 \mid-0.155\end{array}$ \\
\hline 2 & $\begin{array}{l}\text { Systolic Blood Pressure } \\
\text { Diastolic Blood Pressure }\end{array}$ & $\begin{array}{r}0.023 \\
-0.109\end{array}$ & $\begin{array}{l}-0.288 \mid 0.334 \\
-0.391 \mid 0.172\end{array}$ & $\begin{array}{r}-0.556 \\
0.430\end{array}$ & $\begin{array}{c}-0.815 \mid-0.297 \\
0.196 \mid 0.664\end{array}$ & $\begin{array}{r}0.375 \\
-0.674\end{array}$ & $\begin{array}{r}0.121 \mid 0.628 \\
-0.903 \mid-0.445\end{array}$ \\
\hline
\end{tabular}

All models are adjusted for sex, and body mass index.

IMT: intima-media thickness.

of the carotid artery at young adulthood. Diastolic blood pressure at adolescence was negatively associated with carotid IMT and stiffness index $\beta$ of the carotid artery at young adulthood, independently of systolic blood pressure, sex and body mass index, explaining up to $10 \%$ of carotid stiffness at young adulthood. Systolic blood pressure at adolescence was only significantly associated with carotid distensibility at young adulthood. As for hemodynamic values taken at young adulthood, and performing identical adjustments for confounders, PP was significantly associated with both arterial stiffness indices, explaining up to $37 \%$ of the variance in stiffness index $\beta$. Systolic blood pressure at young adulthood was positively associated with carotid stiffness, whereas the inverse was observed for diastolic blood pressure, explaining up to $36 \%$ of carotid stiffness at young adulthood. Collinearity had minimal impact on the results (variance inflation factor $<2.0$ )

Although no significant mean differences were found between PP at adolescence and at young adulthood in both sexes, $16.5 \%$ of the participants had their PP risk category changed during this period (to or from the highest PP tertile). Figure 1 illustrates the odds-ratio for increased early pathological changes in carotid artery structure and stiffness by PP tracking categories. Logistical regression analysis demonstrated that participants in the high PP category at adolescence were at risk for increased carotid IMT at young adulthood $(p<.05)$, even if they had corrected PP at young adulthood. On the contrary, participants with higher PP at adulthood were at risk for increased stiffness regardless of adolescence PP $(p<.05)$. No significant findings were observed when testing systolic or diastolic blood pressure changes, except for those participants with continuous high diastolic blood pressure (OR: 0.167 95\%CI $=0.031-0.912 \mid p=.039)$, and those who normalized their SBP (OR: $0.029 \mid 95 \%$ CI $=0.02-0.372 \mid$ $p=.006)$ at young adulthood, who had lower risk of increased stiffness index $\beta$.

\section{Discussion}

We tracked PP from adolescence to young adulthood and examined its potential role as a determinant of carotid IMT and stiffness. Our main findings were that: (1) several blood pressure parameters are directly associated with vascular properties, but exposure to wide PP at adolescence and young adulthood may be a better predictor of early pathological changes in carotid artery structure and stiffness at young adulthood; (2) adolescents with high PP were at risk for increased carotid IMT at young adulthood, even if they had normalized PP at young adulthood; (3) young adults with high PP were at risk for increased stiffness regardless of adolescence PP.

Only a longitudinal study addressed the association of $\mathrm{PP}$ in adolescence and subclinical atherosclerosis in adults [5]. In the Young Finns Study, exposure to large PP in adolescence was independently associated with increased carotid IMT in adulthood. Each $10 \mathrm{~mm}$ $\mathrm{Hg}$ increment in pulse pressure was associated with a $0.008 \mathrm{~mm}$ increase in carotid IMT. [5]. We extend these findings by showing that exposure to large PP in adolescence is also associated with carotid stiffness, and that lowering PP at young adulthood may not be enough to reverse vascular remodeling, or it may take longer to reduce carotid IMT once you had high PP at adolescence.

A systematic review derived from cross-sectional studies suggested that the contribution to arterial 


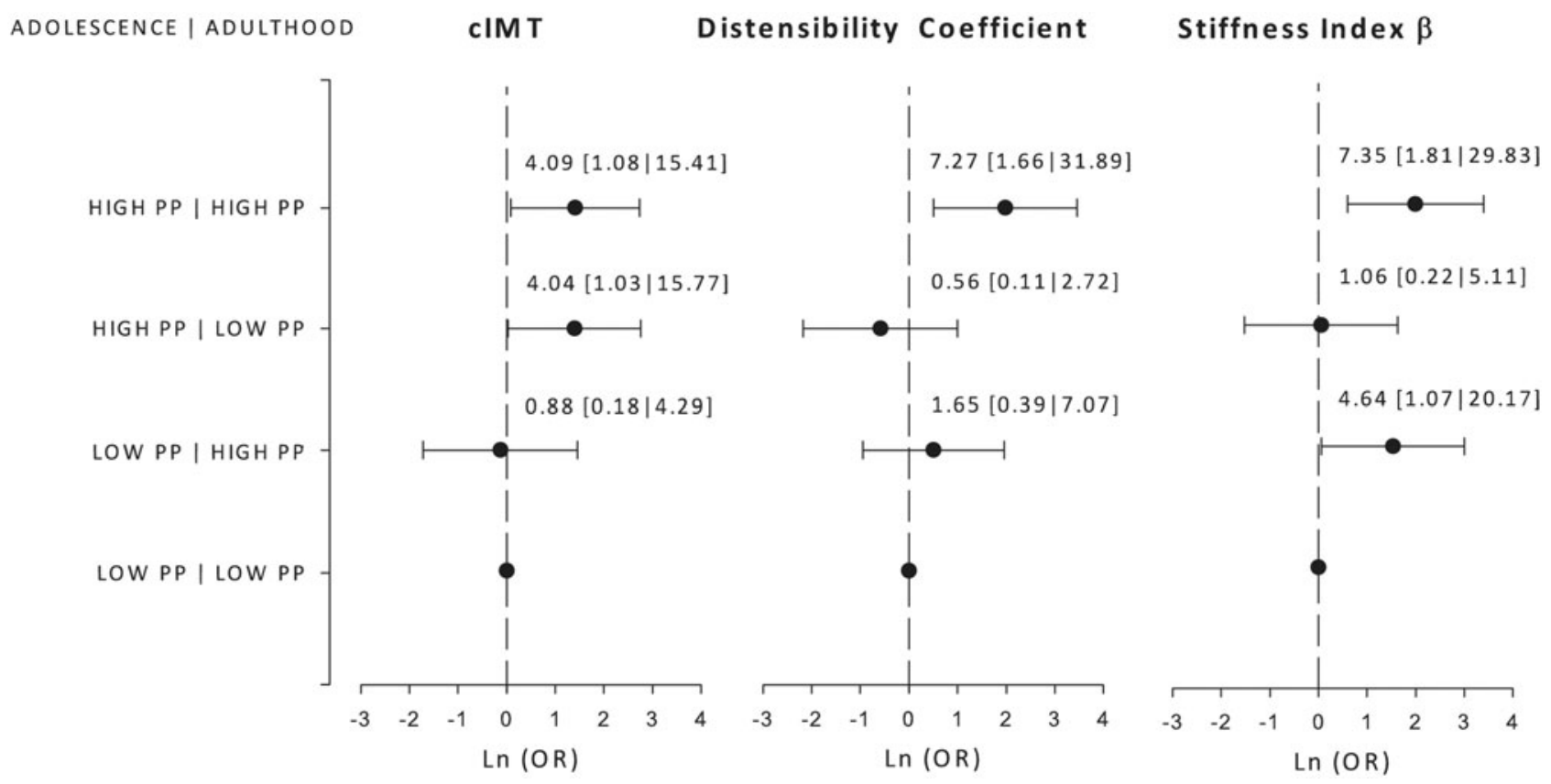

Figure 1. Logistical regression analysis between PP changes from adolescence and early pathological changes of carotid artery structure and stiffness in adulthood. Results are presented as Ln odds-ratio and $95 \% \mathrm{Cl}$ for representation purposes. IMT and stiffness indices are presented as risk categories (i.e. lowest sex-specific tertile for distensibility or highest tertile for stiffness index $\beta$ ). The persistently low PP category was used as the reference group [odds ratio $(\mathrm{OR})=1$ ]. All data are adjusted for sex, mean arterial pressure and body mass index changes. PP: Pulse Pressure; IMT: Intima-Media Thickness; Ln: Logarithm; OR: Odds Ratio.

stiffness of risk factors other than blood pressure was only modest [21]. Epidemiologic studies have emphasized the association between systolic and diastolic blood pressures in adolescence and arterial stiffness in young adulthood [3,4,22]. Subjects with stiffer arteries (as given by distensibility and compliance or Young's elastic modulus) had on average and throughout the whole longitudinal period greater levels of mean arterial pressure, systolic and diastolic blood pressures, respectively, than those with less stiff arteries [3]. However, these studies did not use PP or its changes from adolescence in the prediction of arterial stiffness in adulthood. Considering the present results, that may come as a limitation given the additional information provided by PP both at adolescence and young adulthood. Importantly, a PP reduction from adolescence to young adulthood may have significant benefits in carotid artery stiffness at young adulthood, contrary to what was found for carotid IMT. This suggests that alterations in vasomotor tone may account for changes in arterial wall structure, in line with the idea that changes in arterial stiffness precede those of structural measures [23]. It also suggests that PP tracking can be considered when evaluating lifelong cardiovascular risk, and may be taken into clinical consideration that lends itself toward a therapeutic intervention, although further research is needed.

\section{Limitations}

Our study has several limitations. The tertiles defined from the data distribution for PP, carotid IMT and stiffness indices may not be predictive of risk.

Increased carotid IMT can be seen in children with risk factors. Therefore, it is possible that the early increase in PP in adolescents is a result rather than a cause of increased carotid IMT. However, we deemed this less likely because the young subjects were unaware of and asymptomatic regarding their carotid structure or stiffness levels. Still, our results provide further evidence for the hypothesis that the pulsatile component of blood pressure has a role in the development of increased carotid IMT and stiffness $[3,5]$.

Our findings were confined to subjects in whom complete data for arterial properties were obtained during the follow-up examination from 2013-2015. We have not examined whether blood pressure levels in these subjects differed, at the earlier time point, from those subjects who dropped-out or could not be evaluated.

\section{Conclusion}

PP at adolescence and young adulthood may be a better predictor of early pathological changes in carotid artery structure and stiffness. Whereas carotid IMT in 
young adults appeared to be influenced by PP at adolescence, carotid stiffness depended primarily on current $\mathrm{PP}$.

\section{Acknowledgements}

The authors would like to thank Diogo Abreu, Sara Cunha and Catarina Abreu for the assistance provided and dedication throughout the data collection period.

\section{Disclosure statement}

The authors have no competing interests and take responsibility for all aspects of the reliability and freedom from bias of the data presented and their discussed interpretation.

\section{Funding}

The Portuguese Foundation for Science and Technology funded this project: PTDC/DES/119028/2010.

\section{ORCID}

Xavier Melo (D) http://orcid.org/0000-0003-3934-3986

\section{References}

[1] Mathur KS, Kumar V, Kashyap SK. The natural history of coronary atherosclerosis. Dis Chest. 1964;46:70-77.

[2] Berenson GS. Childhood risk factors predict adult risk associated with subclinical cardiovascular disease. The Bogalusa Heart Study. Am J Cardiol. 2002;90:3L-7L.

[3] Ferreira I, van de Laar RJ, Prins MH, et al. Carotid stiffness in young adults: a life-course analysis of its early determinants: the Amsterdam Growth and Health Longitudinal Study. Hypertension. 2012;59: 54-61.

[4] Li S, Chen W, Srinivasan SR, et al. Childhood blood pressure as a predictor of arterial stiffness in young adults: the Bogalusa Heart Study. Hypertension. 2004;43:541-546.

[5] Raitakari OT, Juonala M, Taittonen L, et al. Pulse pressure in youth and carotid intima-media thickness in adulthood: the cardiovascular risk in young Finns study. Stroke. 2009;40:1519-1521.

[6] Davis PH, Dawson JD, Riley WA, et al. Carotid intimal-medial thickness is related to cardiovascular risk factors measured from childhood through middle age: the Muscatine Study. Circulation. 2001;104: 2815-2819.

[7] Raitakari OT, Juonala M, Kahonen $M$, et al. Cardiovascular risk factors in childhood and carotid artery intima-media thickness in adulthood: the Cardiovascular Risk in Young Finns Study. JAMA. 2003;290:2277-2283.
[8] Li S, Chen W, Srinivasan SR, et al. Childhood cardiovascular risk factors and carotid vascular changes in adulthood: the Bogalusa Heart Study. JAMA. 2003;290:2271-2276.

[9] Juonala M, Järvisalo MJ, Mäki-Torkko N, et al. Risk factors identified in childhood and decreased carotid artery elasticity in adulthood: the Cardiovascular Risk in Young Finns Study. Circulation. 2005;112: 1486-1493.

[10] Juonala M, Viikari JS, Rönnemaa T, et al. Elevated blood pressure in adolescent boys predicts endothelial dysfunction: the cardiovascular risk in young Finns study. Hypertension. 2006;48:424-430.

[11] Safar ME. Systolic blood pressure, pulse pressure and arterial stiffness as cardiovascular risk factors. Curr Opin Nephrol Hypertens. 2001;10:257-261.

[12] Vaccarino V, Holford TR, Krumholz HM. Pulse pressure and risk for myocardial infarction and heart failure in the elderly. J Am Coll Cardiol. 2000;36: 130-138.

[13] Franklin SS, Khan SA, Wong ND, et al. Is pulse pressure useful in predicting risk for coronary heart Disease? The Framingham heart study. Circulation. 1999;100:354-360.

[14] Nichols WW, Nicolini FA, Pepine CJ. Determinants of isolated systolic hypertension in the elderly. J Hypertens Suppl. 1992;10:S73-S77.

[15] Franklin SS, Gustin W, Wong ND, et al. Hemodynamic patterns of age-related changes in blood pressure. The Framingham Heart Study. Circulation. 1997;96:308-315.

[16] Fernandez-Fresnedo G, Rodrigo E, de Francisco AL, et al. Role of pulse pressure on cardiovascular risk in chronic kidney disease patients. J Am Soc Nephrol. 2006;17:S246-S249.

[17] Riddoch CE, Edwards D, Page A, et al. The European Youth Heart Study-cardiovascular disease risk factors in children: rationale, aims, study design, and validation of methods. J Phys Activity Health. 2005;2:15.

[18] Meinders JM, Hoeks AP. Simultaneous assessment of diameter and pressure waveforms in the carotid artery. Ultrasound Med Biol. 2004;30:147-154.

[19] de Onis M, Onyango AW, Borghi E, et al. Development of a WHO growth reference for school-aged children and adolescents. Bull World Health Organ. 2007;85:660-667.

[20] WHO. Obesity: preventing and managing the global epidemic. Report of a WHO consultation. World Health Organ Tech Rep Ser. 2000;894:i-xii, 1-253.

[21] Cecelja M, Chowienczyk P. Dissociation of aortic pulse wave velocity with risk factors for cardiovascular disease other than hypertension: a systematic review. Hypertension. 2009;54:1328-1336.

[22] Raitakari OT, Juonala M, Viikari JS. Obesity in childhood and vascular changes in adulthood: insights into the Cardiovascular Risk in Young Finns Study. Int J Obes (Lond). 2005;29(Suppl 2):S101-S104.

[23] Aggoun Y, Bonnet D, Sidi D, et al. Arterial mechanical changes in children with familial hypercholesterolemia. Arterioscler Thromb Vasc Biol. 2000;20: 2070-2075. 